\title{
POSSIBLE CORRELATIONS BETWEEN AEROBIC POWER AND ANAEROBIC LACTACID CAPACITY IN HANDBALL PLAYERS
}

\author{
Florin TROFIN ${ }^{1 *}$, Cezar HONCERIU ${ }^{1}$ \\ 1 “Alexandru Ioan Cuza” University, Faculty of Physical Education and Sport, Iași, Romania \\ *Corresponding author: florintrofin@gmail.com
}

DOI: $10.35189 /$ iphm.icpesk.2019.47

\begin{abstract}
The study aims to analyse the correlations between aerobic power and anaerobic capacity in male handball players in the First League of Romania. The assessed group consists of 50 players $(24.92 \pm 4.20$ years, $190.5 \pm 6.93 \mathrm{~cm}, 95.18$ $\pm 14.18 \mathrm{~kg}, 20.54 \pm 5.15 \%$ body fat $)$ who play as goalkeepers $(n=7)$, wing players $(n=13)$, backcourt players $(n=23)$ and pivots $(n=7)$. The physical evaluation of subjects aimed to determine their aerobic power by the VamEval test, but also their anaerobic lactacid capacity using the $8 \times 10+10 \mathrm{~m}$ test. Maximum oxygen consumption was estimated at $56.86 \pm 5.00$ $\mathrm{ml} / \mathrm{kg} / \mathrm{min}$, and anaerobic lactacid capacity was $5.55 \pm 3.03 \%$. The statistical analysis of the data revealed a negative correlation between the two physical parameters $(p=0.031)$. Connections were also found between aerobic power and body mass index (BMI), body fat and muscle mass. Thus, there seems to be a close link between the aerobic capacity and the anaerobic lactacid capacity of professional handball players, and between the two, there is a biological link too. The results draw attention to the need to develop aerobic endurance in handball and highlight the links that exist between the body composition of the players and their exercise capacity.
\end{abstract}

Keywords: aerobic power, anaerobic lactacid capacity, handball.

\section{Introduction}

Like other indoor games, handball continues to grow in popularity. It has features such as running speed, energy transmitted by players, competitive effort, technical and tactical approaches. Originating in Berlin (1919) and listed as an Olympic sport in 1972, handball has become a well-known and beloved sport throughout Europe, following its path across the Planet. The game takes place between two teams of 7 players on an area of $20 \mathrm{x} 40 \mathrm{~m}$ (Sporis, 2010).

The sequence of actions during the handball game creates diversity, with the main features being strength, speed, power, and muscle endurance. Although, in combination, these features give the game spectacularity, they are hard to practice. The assessment of the real chances to practice handball is based on the anthropometric characteristics and motor skills. (Lidor \& Arnon, 2000)

Like any organized activity, handball includes specialists who try to organize the game, most of them being technical staff (coaches, physical trainers, physiotherapists, physicians, nutritionists, video analysts, etc.). There are specialised people, outside of the performance sport, interested in the phenomenon. For example, physical education and sport teachers can deepen the handball secrets to share them in school, formally or informally. All these specialists aim to use science for the benefit of progress, which is why handball has become a research topic. The results presented in the literature are intended to support those involved in conducting training so that athletes get the best results.

Through the anthropometric assessment, the coach can perform the primary selection, followed by the physiological, biochemical, biomechanical and psychological ones, which provide information about the athlete's current state that can determine their evolution during that period. Increasing the physical potential leads to increased sport potential and implicitly to the achievement of results in competitions (Sporis, 2010).

Each athlete has a profile that can be assessed qualitatively and quantitatively; therefore, following a specific assessment, a description of the athlete can be made based on the results obtained in physical tests, which contributes to the individualisation of training (Trofin \& Honceriu, 2016). Applying a physical test battery designed to achieve the physical profile of the athlete must be done carefully, because each test, however well designed, generates errors that can be human, technical or otherwise (Michalsik, \& Aagaard, 2015a).

The aerobic physical component of the athlete has an important contribution to optimal performance during the game. The argument is given by the energy substrate consumed during the official game play, which is $90 \%$ metabolised through the aerobic pathway. The distance run by a player in a match, approximately 4-6 km, is travelled with a heart rate of $80-90 \%$ of the maximum (Loftin, Anderson, Lytton, Pittman, \& Warren, 1996). In addition, the relationship established between maximum oxygen consumption and level of play has been demonstrated (Gorostiaga, Granados, Ibáñez, \& Izquierdo, 2005; Rannou, Prioux, Zouhal, Gratas-Delamarche, \& Delamarche, 2001). 
Estimating maximum oxygen consumption can be done by field tests the duration of which should be between 8 and 17 minutes, the values obtained outside this range being erroneous (Yoon, Kravitz, \& Robergs, 2007). Most of them involve a progressive increase in exercise intensity and reaching the body's upper limit, which results in the inability to execute the movement at the required pace. Such a test is performed over $20 \mathrm{~m}$ with a constant progression speed (Aadland, Andersen, Lerum, \& Resaland, 2018).

Field tests are equivalent in the lab, so monitoring an athlete can be done indoors on the treadmill or cycloergometer (Trofin, Abălașei, Drosescu, \& Cojocaru, 2013b). The means of assessing maximum aerobic speed can take different forms and can be adapted to the particularities of the athlete: age, gender, experience, etc. (Berthoin et al., 1994). Physical tests must be specific to handball, imitating field structures and simulating high physiological stress, in order to use the results in the training of athletes (Buchheit et al., 2009).

In high-performance players, maximum oxygen consumption is high, but there are no significant differences between positions (Zapartidis, Kororos, \& Christodoulidis, 2011).

The recent change in the development of the game is reflected in higher demands of anaerobic metabolism with lactic acid release in the internal environment. Thus, players need to adapt their tolerance to the acidic environment, the neutralisation of $\mathrm{H}+$ ions becoming important to maintain their ability to perform repeated sprints. The player's aerobic capacity makes possible the intake of oxygen, limiting the accumulation of lactic acid in large amounts, which would lead to functional disability of the muscles (Chelly et al., 2011).

For players, psychological comfort can be created, knowing that increased oxygen consumption and maximum aerobic power can improve self-esteem, which helps them in the difficult times of their sport performance (Trofin, Honceriu, \& Cojocaru, 2013a).

We aim to analyse the correlation between aerobic power and anaerobic capacity in a group of 50 professional male handball players in the First League of Romania. Such research was carried out by other specialists, who have shown that high aerobic power leads to exercise capacity in the same anaerobic lactacid conditions due to the support provided by the aerobic system to the anaerobic one (da Silva, Guglielmo, \& Bishop, 2010; Turner \& Stewart, 2013).

\section{Material and Methods}

The research involved 50 professional male handball players in the First League of Romania. They were aged 19 to 32 years and practiced handball in an organized manner for $12.38 \pm 4.54$ years. All players were involved in the competition system during the research.

Our scientific approach has started from the assumption that there is a correlation between maximum oxygen consumption and anaerobic lactacid capacity in senior male handball players. To demonstrate this, we need to assess both parameters and other data to describe as precisely as possible the group of athletes. They were assessed only once during the pre-competitive period of the regular season.

Table 1 includes values of the players' morphofunctional parameters that quantify: age, experience in organized sports training, height, body mass, body mass index (BMI), body fat, muscle mass and visceral fat. Determining these data was made possible by investigating the athletes, as well as by measuring them directly using a Bosh GLM80, a metal square and an Omron BF511 body analyser. The first two instruments were used to measure the height (Trofin et al., 2013b), and the analyser, for the rapid determination of body mass, BMI, adipose tissue, muscle mass, and fat around internal organs. The analyser works on the basis of bioimpedance.

Athletes were notified of the study, and then went through standard procedures for data collection. All players were medically fit for this effort.

Table 1. Morphofunctional characteristics of the research group (mean \pm standard deviation)

\begin{tabular}{lc}
\hline \multicolumn{1}{c}{ Parameter } & Value \\
\hline age (years) & $24.92 \pm 4.20$ \\
experience (years) & $12.38 \pm 4.54$ \\
height $(\mathrm{cm})$ & $190.5 \pm 6.93$ \\
body mass $(\mathrm{kg})$ & $95.18 \pm 14.18$ \\
BMI $(\mathrm{kg} / \mathrm{m} 2)$ & $25.65 \pm 4.68$ \\
body fat $(\%)$ & $20.54 \pm 5.15$ \\
muscle mass $(\%)$ & $37.99 \pm 4.24$ \\
visceral fat & $7.08 \pm 1.91$ \\
\hline
\end{tabular}




\section{Anaerobic lactacid capacity}

The anaerobic lactacid capacity is the feature that gives the player the potential to perform effort with maximum intensity in the conditions in which the energy substrate is metabolised without the involvement of oxygen and with the resultant lactic acid. This parameter was tested on a wooden surface, right in the sports hall where the handball team performed their training and official games.

The chosen test is $8 \times 10+10 \mathrm{~m}$ (Trofin, Honceriu, \& Abălaşei, 2018). For the accuracy of the measurements, a Tracktronix electronic timing system was used. Its resolution is 0.001 seconds, and the error is only \pm 0.0001 seconds. The distance measurements were made with a wheel ruler, and the chalk marks were used for the athletes to have visible landmarks during the test.

The markings were two parallel lines (A and B) drawn on the ground, $1 \mathrm{~m}$ long and $20 \mathrm{~m}$ apart. In the middle of the distance, between the two lines, a photocell of the timing system is placed transversally. Following the signal of the evaluator, who manually starts the timer when prepared, the player sprints from line A to B passing through the photocell gateway that is set to "split" mode. The test involves 8 sprints over the distance between the two lines so that, when reaching line B, the player steps on it or slightly crosses it and returns to line A, resuming the action until completion of the route. Throughout the run, maximum speed will be maintained even if the athlete falls at the end of the run. After passing through the photocell gateway, the stopwatch will indicate an intermediate time that will be written on a result sheet.

Centralisation in the database and result processing generated two synthetic test parameters: $\mathrm{T} 7$ and $\mathrm{D} \%$ $\left(\left(\mathrm{T}_{\mathrm{MD}} / \mathrm{T}_{\min }\right) \times 100-100\right)$. The former counts the time of the $140-\mathrm{m}$ run through the, round-trip $=20 \mathrm{~m}$. An athlete with good speed, strength and agility will record the shortest time possible. The latter index, D\%, represents the resulting percentage difference between the average of the 7 times obtained during the run for each $10+10 \mathrm{~m}$ $\left(\mathrm{T}_{\mathrm{MD}}\right)$ and the best time of all $\left(\mathrm{T}_{\mathrm{min}}\right)$. High tolerance to anaerobic lactacid effort will result in a $\mathrm{D} \%$ as low as 0 (Trofin et al., 2018).

Being a test that quickly depletes the athletes' glycolysis resources, it can be performed only once, therefore the next test is possible only when energy resources are restored and metabolic waste is metabolised.

\section{Maximum oxygen consumption}

In the same location, on the same day, 30 minutes after the previous test, maximum oxygen consumption was measured using a train test. There are two parallel lines on the ground, $20 \mathrm{~m}$ apart. The width of the room had the exact size for our needs. Each player' heart rate was monitored throughout the test using a Polar Belt. Heart rate tracking during a cardiovascular system test has significant applicability, athletes having different responses depending on their sports experience, level of training, genetic endowments, mental qualities, etc.

We used the VamEval test, which was designed by researchers from the universities of Montreal and Bordeaux (Cazorla, Léger, \& Marini, 1993), but was then adapted and changed. An audio device emits sounds that dictate the running speed between the two lines, with return at each signal. The test assumes that the running speed increases progressively, starting at $8.5 \mathrm{~km} / \mathrm{h}$ and continuing with the addition of $0.5 \mathrm{~km} / \mathrm{h}$ every minute. Athletes maintain the given pace until they end up exhausting the energy substrate specific to the effort, at which time the level reached is recorded. Each level corresponds to a maximum aerobic speed (MAS) based on which maximum oxygen consumption can be approximated. (Trofin et al., 2013b)

\section{Results}

The obtained data series were entered into a database of the GraphPad Prism 6 statistical analysis software and then processed to test the research hypothesis.

Our research group reached a maximum oxygen consumption of approximately $56.86 \pm 5.00 \mathrm{ml} / \mathrm{kg} / \mathrm{min}$. Individual values were assessed using the VamEval test equivalence tables.

The $8 \times 10+10 \mathrm{~m}$ test revealed a result of $5.55 \pm 3.03 \%$ for the anaerobic lactacid capacity of the group.

The obtained values ranked the rated players among those evaluated in other studies, the results being similar to those reported by other authors. The difficulty arises when comparing the anaerobic lactacid capacity, because the test used is relatively new, and studies done with it have other scientific nuances.

A number of 26 handball players in the first half of the Danish leagues $(26.4 \pm 3.1$ years, $90.9 \pm 9.0 \mathrm{~kg}, 188.9 \pm$ $6.3 \mathrm{~cm}, 7.2 \pm 3.6$ years of experience) had a maximum oxygen consumption of $57.0 \pm 4.1 \mathrm{ml} / \mathrm{min} / \mathrm{kg}$ (Michalsik, Madsen, \& Aagaard, 2015b). This value is very close to the one recorded in our study. 
By testing 46 handball players aged 19-28, it has been found that VO2max is similar for national and international handball players. Differences do not exist in athletes preparing for speed tests, but endurance athletes have a considerable advantage (Rannou et al., 2001).

The collected results were analysed using the Graph Pad Prism 6 software, which generates descriptive statistics, as well as the synthesis of Pearson's correlation tests. The analysis was made for the relationships established between age, body mass, body mass index, body fat, muscle mass, time needed to cover the distance in the $8 \times 10+10 \mathrm{~m}$ test, synthesis index of anaerobic lactate capacity and maximum oxygen consumption. The $\mathrm{R}$ coefficient was calculated for each pair of data series, the significance being assessed according to the scale established by Evans (1996).

Table 2. Correlation between the research variables

\begin{tabular}{lcccccccc}
\hline & $\begin{array}{c}\text { age } \\
(\text { years })\end{array}$ & $\begin{array}{c}\text { body mass } \\
(\mathrm{kg})\end{array}$ & $\begin{array}{c}\text { BMI } \\
(\mathrm{kg} / \mathrm{m} 2)\end{array}$ & $\begin{array}{c}\text { body fat } \\
(\%)\end{array}$ & $\begin{array}{c}\text { muscle mass } \\
(\%)\end{array}$ & $\begin{array}{c}\mathrm{T}_{140 \mathrm{~m}} \\
(\mathrm{~s})\end{array}$ & $\begin{array}{c}\mathrm{D} \% \\
(\mathrm{ml} / \mathrm{kg} / \mathrm{min})\end{array}$ \\
\hline age (years) & & -0.360 & -0.188 & -0.153 & 0.180 & -0.203 & -0.046 & 0.257 \\
body mass $(\mathrm{kg})$ & -0.360 & & 0.616 & 0.661 & -0.523 & 0.621 & 0.395 & -0.653 \\
BMI (kg/m2) & -0.188 & 0.616 & & 0.586 & -0.422 & 0.454 & 0.341 & -0.532 \\
body fat (\%) & -0.153 & 0.661 & 0.586 & & -0.669 & 0.637 & 0.535 & -0.681 \\
muscle mass (\%) & 0.180 & -0.523 & -0.422 & -0.669 & & -0.426 & -0.273 & 0.411 \\
$\mathrm{~T}_{140 \mathrm{~m}}(\mathrm{~s})$ & -0.203 & 0.621 & 0.454 & 0.637 & -0.426 & 0.530 & -0.685 \\
D\% & -0.046 & 0.395 & 0.341 & 0.535 & -0.273 & 0.530 & -0.306 \\
VO2max (m1/kg/min) & 0.257 & -0.653 & -0.532 & -0.681 & 0.411 & -0.685 & $\mathbf{- 0 . 3 0 6}$ & \\
\hline
\end{tabular}

Table 2 contains the Pearson correlation coefficient values for each parameter pair assessed in the study.

These values show a poor and very poor correlation $(r>-0.39$ and $r<0.39)$ of age with the other parameters, which means that age does not influence, in professional handball players, body composition and effort, whether it is aerobic or anaerobic.

Body mass strongly correlates with body mass index $(r=0.616)$, body fat $(r=0.661)$, long-distance running speed under anaerobic conditions, and aerobic endurance $(\mathrm{r}=-0.653)$. We deduce that a body mass will lead to increased BMI, which is normal due to its inclusion in the calculation formula. The correlation is negative for sports performance, because a high BMI will lead to poor health and performance (Sedeaud et al., 2014). Body fat is the physical component that increases body mass, and this phenomenon is detrimental to the physical performance of the athlete (Silvestre, West, Maresh, \& Kraemer, 2006). A strong link is established between body mass and maximum oxygen consumption $(\mathrm{r}=-0.653)$, which regresses when the body moves a significant inactive mass.

The results show the difference between the correlation of BMI with body fat $(\mathrm{r}=0.586)$ and between the same BMI and muscle mass (-0.422). The two relationships are in different ways of average power and show that muscle mass can have a positive effect on sports performance.

Body fat is strongly negatively correlated with muscle mass $(r=-0.669)$ and aerobic endurance $(r=-0.681)$. This demonstrates that athletes need to be very careful about diet, because it can negatively influence body composition and implicitly physical performance (Loucks, Kiens, \& Wright, 2011). The same type of connection is also achieved with the anaerobic lactacid effort $(\mathrm{r}=0.535)$.

Muscle mass does not significantly correlate with the two parameters of exercise capacity: anaerobic $(\mathrm{r}=$ $0.273)$ and aerobic $(r=0.411)$. Thus, a player with overdeveloped muscle mass does not increase their physical performance in handball.

The handball game entails the formation of lactic acid in the muscle cell, its concentration being $1.5 \pm 0.5 \mathrm{mM}$ after warm-up, $3.7 \pm 1.6 \mathrm{mM}$ after the first half and $4.8 \pm 1.9 \mathrm{mM}$ at the end of a game (Michalsik et al, 2015b).

Some studies have demonstrated the link between aerobic endurance and anaerobic lactate capacity (Turner \& Stewart, 2013). If the latter were evaluated by field tests using running distances less than $40 \mathrm{~m}$, the effortrecovery would be between 1: 4 and 1: 5 (da Silva et al., 2010). On the opposite side, there are studies that denote the existence of a link between aerobic and anaerobic exercise capacity (Pyne, Saunders, Montgomery, Hewitt, \& Sheekan, 2008).

In our research, the running time over $140 \mathrm{~m}$ from the $8 \times 10+10 \mathrm{~m}$ test strongly correlates with $\mathrm{VO} 2 \mathrm{max}(\mathrm{r}=$ -0.685 ). As shown in the literature, the maximum level of oxygen consumption is conditional on recovery after an anaerobic lactacid effort (Alemdaroğlu, 2012). Instead, the area of interest of our study shows that there is a poor 
negative relationship between maximum oxygen consumption and anaerobic lactate capacity $(r=-0.306)$, which leads to the invalidation of the research hypothesis. Therefore, the ability of a handball player to sustain an effort with maximum aerobic intensity is not supported by his ability to sustain intensive efforts to release lactate in the internal environment (Figure 1).

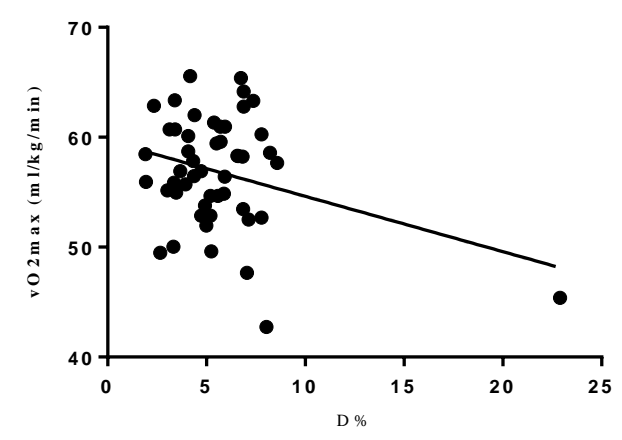

Figure 1. Linear regression of the data series

\section{Conclusion}

The age of male handball players is not related to the synthetic parameters of exercise capacity, both aerobic and anaerobic. In the case of our athletes, age is not a factor that leads to a decrease in physical potential.

The body mass of handball players is closely related to BMI, which is normal due to its inclusion in the calculation formula. At the same time, body mass establishes strong connections with body fat, long-distance running speed and aerobic capacity of the body. An athlete with high body mass will be slower and less resistant.

The percentage of body fat is a negative factor for achieving sports performance, leading to a decrease in the weight of the active body mass and therefore to fatigue.

Quantitatively, muscle mass does not determine aerobic or anaerobic potential. It is probably the type of muscle fibre that determines the physical capacity of the athlete.

The handball players analysed by us have a low correlation between anaerobic lactacid capacity and maximum oxygen consumption, which means that the potential to maintain exercise intensity at the end of a test to assess maximum oxygen consumption is determined by other factors. These factors may be psychological in nature.

The literature is controversial about the topic addressed in this study, which can be deepened in future research whose target might be athletes with other demographic features.

\section{References}

Aadland, E., Andersen, L. B., Lerum, Ø., \& Resaland, G. K. (2018). The Andersen aerobic fitness test: New peak oxygen consumption prediction equations in 10 and 16-year olds. Scandinavian Journal of Medicine \& Science in Sports, 28(3), 862-872. https://doi.org/10.1111/sms.12985

Alemdaroğlu, U. (2012). The relationship between muscle strength, anaerobic performance, agility, sprint ability and vertical jump performance in professional basketball players. Journal of Human Kinetics, 31(1), 149-158. https://dx.doi.org/10.2478\%2Fv10078-012-0016-6

Berthoin, S., Gerbeaux, M., Turpin, E., Guerrin, F., Lensel-Corbeil, G., \& Vanderdorpe, F. (1994). Comparison of two field tests to estimate maximum aerobic speed. Journal of Sports Sciences, 12(4), 355-362. https://doi.org/10.1080/02640419408732181

Buchheit, M., Laursen, P. B., Kuhnle, J., Ruch, D., Renaud, C., \& Ahmaidi, S. (2009). Game-based training in young elite handball players. International Journal of Sports Medicine, 30(4), 251-258. https://doi.org/10.1055/s-0028-1105943

Cazorla, G., Léger, L., \& Marini, J.-F. (1993). Les épreuves d'effort en physiologie. Épreuves et mesures du potentiel aérobie dans les épreuves de la valeur physique. Travaux et Recherches en EPS, 7, 95-119.

Chelly, M. S., Hermassi, S., Aouadi, R., Khalifa, R., Van den Tillaar, R., Chamari, K., \& Shephard, R. J. (2011). Match analysis of elite adolescent team handball players. The Journal of Strength \& Conditioning Research, 25(9), 2410-2417. https://doi.org/10.1519/JSC.0b013e3182030e43 
da Silva J. F., Guglielmo, L. G., \& Bishop, D. (2010). Relationship between different measures of aerobic fitness and repeated sprint ability in elite soccer players. The Journal of Strength \& Conditioning Research, 24(8), 2115-2121. https://doi.org/10.1519/JSC.0b013e3181e34794

Evans, J. D. (1996). Straightforward statistics for the behavioral sciences. Pacific Grove: Brooks/Cole Pub. Co.

Gorostiaga, E. M., Granados, C., Ibáñez, J., \& Izquierdo, M. (2005). Differences in physical fitness and throwing velocity among elite and amateur male handball players. International Journal of Sports Medicine, 26(3), 225232. https://doi.org/10.1055/s-2004-820974

Lidor, R., \& Arnon, M. (2000). Developing indexes of efficiency in basketball: Talk with coaches in their own language. Kinesiology, 32(2), 31-41.

Loftin, M., Anderson, P., Lytton, L., Pittman, P., \& Warren, B. (1996). Heart rate response during handball singles match-play and selected physical fitness components of experienced male handball players. Journal of Sports Medicine and Physical Fitness, 36(2), 95-99. Retrieved from https://www.researchgate.net/publication/14307534_Heart_rate_response_during_handball_singles_matchplay_and_selected_physical_fitness_components_of_experienced_male_handball_players

Loucks, A. B., Kiens, B., \& Wright, H. H. (2011). Energy availability in athletes. Journal of Sports Sciences, 29(Suppl. 1), 15-24. https://doi.org/10.1080/02640414.2011.588958

Michalsik, L. B., \& Aagaard, P. (2015a). Physical demands in elite team handball: Comparisons between male and female players. Journal of Sports Medicine and Physical Fitness, 55(9), 878-891. Retrieved from https://www.ncbi.nlm.nih.gov/pubmed/24947813

Michalsik, L. B, Madsen, K., \& Aagaard, P. (2015b). Physiological capacity and physical testing in male elite team handball. Journal of Sports Medicine and Physical Fitness, 55(5), 415-429. Retrieved from https://www.ncbi.nlm.nih.gov/pubmed/24402441

Pyne, D. B., Saunders, P. U., Montgomery, P. G., Hewitt, A. J., \& Sheekan, K. (2008). Relationships between repeated sprint testing, speed, and endurance. The Journal of Strength \& Conditioning Research, 22(5), 16331637. https://doi.org/10.1519/JSC.0b013e318181fe7a

Rannou, F., Prioux, J., Zouhal, H., Gratas-Delamarche, A., \& Delamarche, P. (2001). Physiological profile of handball players. Journal of Sports Medicine and Physical Fitness, 41(3), 349-353. Retrieved from https://www.ncbi.nlm.nih.gov/pubmed/11533566

Sedeaud, A. M., Marc, A., Marck, A., Dor, F., Schipman, J., Dorsey, M., ...Toussaint, J.-F. (2014). BMI, a performance parameter for speed improvement. PloS one, 9(2): e90183. https://dx.doi.org/10.1371\%2Fjournal.pone.0090183

Silvestre, R., West, C., Maresh, C. M., \& Kraemer, W. J. (2006). Body composition and physical performance in men's soccer: A study of a National Collegiate Athletic Association Division I team. The Journal of Strength \& Conditioning Research, 20(1), 177-183. https://doi.org/10.1519/R-17715.1

Sporis, G. V., Vuleta, D., Vuleta, D. Jr, \& Milanović, D. (2010). Fitness profiling in handball: Physical and physiological characteristics of elite players. Collegium Antropologicum, 34(3), 1009-1014. Retrieved from https://www.ncbi.nlm.nih.gov/pubmed/20977096

Trofin, P. F., \& Honceriu, C. (2016). Pilot study for the assessment of (traction) force at junior football players (15-18 years old). Sport \& Society, 16(1), 61-72.

Trofin, P. F., Honceriu, C., \& Abălașei, B. (2018). Pilot study on evaluation of anaerobic lactacid capacity in reduced field football. Sport \& Society, 18(1), 63-76.

Trofin, P. F., Honceriu, C., \& Cojocaru, D. (2013a). Comparative study on the assessment of VO2max by ergospirometrie or field test. Sport \& Society, 111-117.

Trofin, P. F., Abălașei, B., Drosescu, P., \& Cojocaru, D. (2013b). Study on the correlation between self-esteem, physical capacity of effort and the somatometric parameters. Sport \& Society, 13(2),170-178.

Turner, A. N., \& Stewart, P. F. (2013). Repeated sprint ability. Strength and Conditioning Journal, 35(1), 37-41. Retrieved from https://journals.lww.com/nsca-scj/Fulltext/2013/02000/Repeat_Sprint_Ability.5.aspx

Yoon, B. K., Kravitz, L., \& Robergs, R. (2007). VO2max, protocol duration, and the VO2 plateau. Medicine \& Science in Sports \& Exercise, 39(7), 1186-1192. https://doi.org/10.1249/mss.0b13e318054e304

Zapartidis, I., Kororos, P., \& Christodoulidis, T. (2011). Profile of young handball players by playing position and determinants of ball throwing velocity. Journal of Human Kinetics, 27(1), 17-30. https://doi.org/10.2478/v10078-011-0002-4 